Caligrama, Belo Horizonte, v.19, n.2, p. 197-216, 2014

\title{
As variantes lexicais de carne-seca no norte mato-grossense
}

\section{The lexical variations of jerked beef in Southern Mato Grosso}

Manoel Mourivaldo Santiago-Almeida

Universidade de São Paulo (USP), São Paulo, São Paulo, Brasil.

horas@terra.com.br

Neusa Inês Philippsen

Universidade do Estado de Mato Grosso (UNEMAT), Cáceres, Mato Grosso, Brasil. neinph@yahoo.com.br

Resumo: Este artigo apresenta um estudo de cunho sócio-geolinguístico fundamentado na teoria da variação laboviana, na concepção de norma de Coseriu (1979) e nas noções de estatística lexical de Muller (1968), e se propõe a refletir sobre a variedade do português falado em quatro pontos da região norte mato-grossense. São apresentados, para tanto, registros e análise das variantes lexicais do tema carne-seca. O resultado dessa análise sugere que as influências regionais que constituíram e ainda constituem o português falado nesse espaço geográfico são oriundas do contato de todos os dialetos e idioletos trazidos pelos migrantes de suas regiões de origem. Trata-se, portanto, de um recorte da linguagem utilizada nessa comunidade para representar o mundo sociocultural que a cerca.

Palavras-chave: diversidade linguística; variantes semântico-lexicais; norte de Mato Grosso; constituição do português brasileiro.

Abstract: This article presents a socio-geolinguistic study founded on the Labovian variation theory, on the principle conception by Coseriu (1979) and on the lexical statistics notions by Muller (1968). It aims to ponder about the variety of the Portuguese language spoken in four sites of the North region of Mato Grosso. Records and analysis of the variants are presented about the theme jerked beef. The result of this analysis suggests 
that the regional influences that have constituted the spoken Portuguese in that geographical space are resultant of the contact with all the dialects and idiolects brought by migrants from their original regions. Therefore, it is all about a language cutting used in that community to represent the socio-cultural world that surrounds it.

Keywords: linguistic diversity; semantic-lexical variants; Northern Mato Grosso; constitution of Brazilian Portuguese.

\section{Preparos iniciais}

Este texto, que se fundamenta nos princípios da geolinguística contemporânea e da sociolinguística variacionista, tem como principal propósito, a partir da análise do tema carne-seca, refletir sobre o português falado em quatro municípios do norte de Mato Grosso e sobre como a pluralidade de normas linguísticas e culturais influencia em sua formação e expansão na região abrangida pelos territórios de Cláudia, Santa Carmem, Sinop e Vera (figura 1). Trata-se de uma parte da região classificada por Nascentes (1953) - conforme a divisão dialetal que fez no Brasil - como território incaracterístico e, também por esse motivo, ausente na rede de pontos do Projeto ALiB (Atlas Linguístico do Brasil) (PROJETO, 2013a).

A intenção ampla, portanto, é apresentar a descrição e análise de um recorte do falar da região de acordo com fatores diatópicos e aspectos de natureza sociocultural e oferecer, assim, um breve estudo dessa variedade do português brasileiro (PB) que pode ser considerada como se ainda estivesse em seu estágio de formação. Essa constatação pode ser averiguada, especificamente, quando se observam as variantes lexicais usadas pelos moradores dessa região para o tema carne-seca. Isso permite verificar, no nível semântico-lexical, como a variedade linguística e as implicações de natureza sociocultural foram e ainda são constituídas nessa região norte mato-grossense que, até então, foi investigada exclusivamente por Philippsen (2013). 


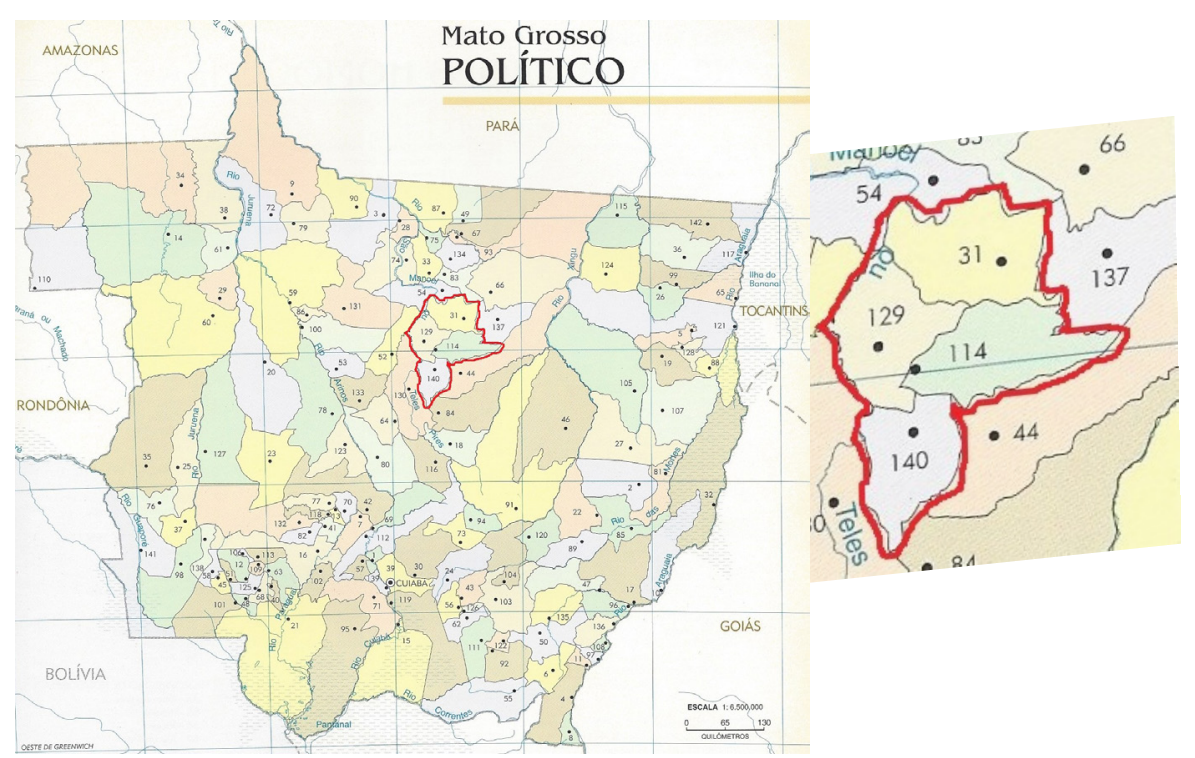

Figura 1 - Mato Grosso (31. Cláudia; 114. Santa Carmen; 129. Sinop; 140. Vera) Fonte: Miranda e Amorim (2001, p. 11).

\section{Formação geopolítica da região e aporte teórico-metodológico}

Esta breve contextualização histórica tem como fonte Oliveira (1982), Panosso Netto (2000) e Souza (2004). Entre os anos de 1970 e 1980, estimuladas pelos "programas especiais" de incentivos fiscais concedidos pelo governo federal, foram registradas trinta e três empresas privadas que implantaram oitenta e oito Projetos de Colonização no norte de Mato Grosso. Dente todas, destacou-se a Colonizadora Sinop (Sociedade Imobiliária do Noroeste do Paraná Ltda.) que inicia suas atividades no Estado em 1971, época da aprovação do projeto de aquisição das terras da Gleba Celeste ${ }^{1}$ pelo Instituto Nacional de Colonização e Reforma Agrária (INCRA).

O primeiro lote de terra adquirido foi denominado Núcleo Colonial Celeste 1 e dividido em três partes: a primeira, com 63.741,30 ha., recebeu o nome de Vera; a segunda, com 64.407,67 ha., foi chamada de Santa Carmem; e a terceira, com 59.519,00 ha., foi denominada Sinop. Em

\footnotetext{
${ }^{1}$ Grande extensão de terras na pré-amazônia mato-grossense, então pertencente ao município de Chapada dos Guimarães e que deu início à colonização do "Núcleo Colonial Celeste" (SOUZA, 2004).
} 
meados da década de setenta, a mesma Colonizadora comprou mais 80.000 ha. e criou o Núcleo Colonial Celeste 2, que recebeu o nome Cláudia. De acordo com o plano de urbanismo rural projetado pelo INCRA, Sinop foi classificada como "Rurópolis"; Vera, Santa Carmem e Cláudia como "Agrópolis"; e os centros convergentes rurais como "Agrovilas".

Atualmente, Vera possui uma população de 10.235 habitantes que atua em atividades relacionadas à economia madeireira e à agricultura no cultivo de soja, arroz e o milho. Santa Carmem, com uma população de 4.021 habitantes, atua com a indústria madeireira, agricultura, agropecuária e prestação de serviços. Sinop, que é a quarta maior de Mato Grosso em população, conta com 111.643 habitantes, e sua economia é diversificada e é conhecida como polo educacional porque nela há um campus da Universidade Federal, um da Universidade do Estado e outras faculdades particulares. Cláudia possui uma população de 10.635 habitantes, apresentando, no momento, uma economia em que se destacam, na agricultura, as produções de arroz, soja, milho, feijão e coco; na pecuária, os sistemas de exploração de gado de corte e leite pelo sistema extensivo ${ }^{2}$.

A pluralidade de falares que se encontram nessas cidades modelou-se, por sua vez, a partir do Projeto de Integração Nacional $(\mathrm{PIN})^{3}$ que possibilitou a vinda de gentes oriundas de diferentes Estados brasileiros (São Paulo, Goiás, Rio Grande do Sul, Paraná, Santa Catarina, Sergipe, Bahia, Espírito Santo e Paraíba), descendentes de italianos, alemães, japoneses, suecos, ingleses, portugueses, ucranianos, poloneses, espanhóis, indígenas e africanos. Essa pluralidade de migrantes é também atestada pelos vinte pioneiros entrevistados para este estudo.

O processo de ocupação do norte mato-grossense está vinculado ao contexto de colonização do país. E por isso é preciso considerar as incursões para esse espaço geográfico desde o início das explorações bandeirantes e monçoeiras, já no século XVII, e mesmo muito antes disso, se considerarmos os caminhos percorridos pelos povos indígenas, fundamentalmente dos

${ }^{2}$ Os dados referentes às informações populacionais das quatro cidades foram apreendidos do censo de 2010 (IBGE, 2010).

${ }^{3}$ O PIN, criado pelo Decreto-Lei ${ }^{\circ} .1 .106$, de junho de 1970, tinha como finalidade específica financiar o plano de obras de infraestrutura das regiões compreendidas nas áreas de atuação da Superintendência do Desenvolvimento do Nordeste (SUDENE) e da Superintendência de Desenvolvimento da Amazônia (SUDAM) e promover sua rápida integração à economia nacional. A primeira etapa do PIN compreendeu o Plano de Irrigação do Nordeste e a construção das rodovias Transamazônica e da CuiabáSantarém (MÜLLER; CARDOSO, 1977). 
kayabi, expulsos dessa região em nome da "civilização" e do progresso, mas que deixou registro na toponímia, principalmente nos rios, como também na fauna e na flora: Kayabi, Xingu, Tapajós, Paranatinga, Curupy, itaúba, cambará, mutum, paca, cutia, entre tantos outros exemplos.

O espírito empreendedor tropeiro também não pode ser desconsiderado, visto que, ao se estabelecer a rota dos tropeiros - de Viamão (RS) a São Paulo e às Minas Gerais - desenvolve-se o fortalecimento do comércio e estimula-se a interiorização do Brasil. Posteriormente, novas rotas passaram a ser investigadas pelos exploradores tropeiros durante $\mathrm{o}$ processo de criação das Capitanias de Mato Grosso e Goiás 4 .

Convém acentuar que a eleição desses quatro municípios foge à proposta de estudos sobre diversidade linguística pensada por Nascentes (1953), que aponta as seguintes divisão e subdivisão de falares (figura 2): norte = amazônico e nordestino; sul = baiano, mineiro, fluminense e sulista; além de um espaço delimitado ao oeste e ao norte de Mato Grosso, parte de Goiás, de Rondônia e do atual território de Tocantins, que denomina como "território incaracterístico".

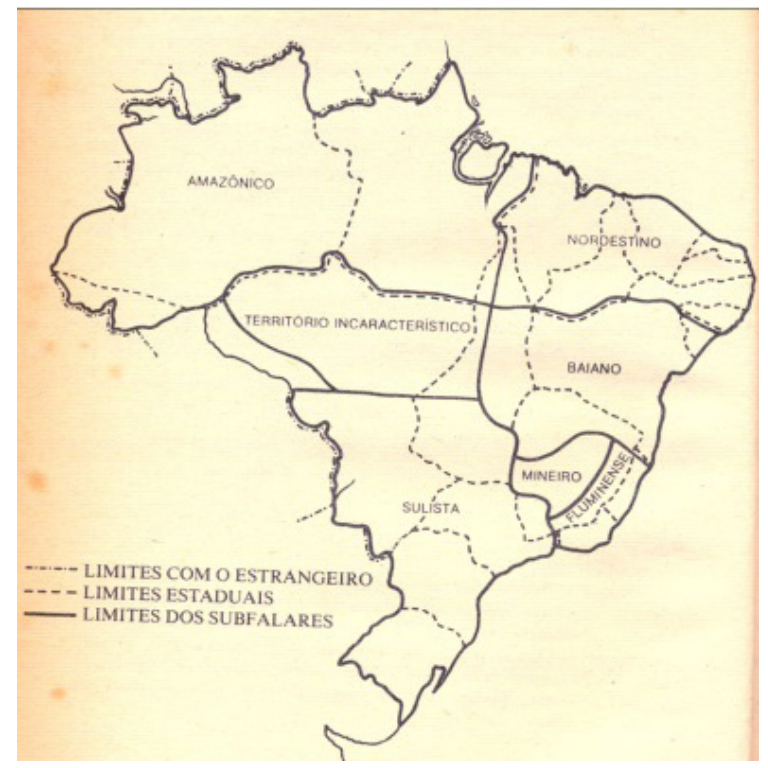

Figura 2 - Divisão de falares no território brasileiro, conforme Nascentes (1953)

Fonte: Projeto (2013b)

\footnotetext{
${ }^{4}$ Fundadas por um Alvará datado de 09/05/1748 e emitido por Dom João V.
} 
Essa divisão adotada por Nascentes, como já dissemos, influenciou bastante na composição da rede de pontos utilizada pelo Projeto $\mathrm{ALiB}$, conforme aparece descrito nos Critérios de seleção de localidades indicados no site do Projeto, pois "muito contribuiu para a escolha das localidades a consulta aos pontos sugeridos por Antenor Nascentes [...] sido mantidas as localidades que ainda se mostravam pertinentes para os objetivos do trabalho" (PROJETO, 2013a).

Ainda que estudos linguísticos mais recentes atestem validade à divisão dialetal do Brasil realizada por Nascentes, tal como o faz Cardoso (1999), o norte mato-grossense continua a ser visto como espaço incaracterístico e com insuficiência demográfica para a realização de pesquisas geolingüísticas. Compreendemos, contudo, em consonância com Almeida (2008), que deixar de registrar os falares de comunidades linguísticas em formação pode levar ao apagamento das realizações linguísticas e ao silenciamento dos fenômenos linguísticos regionais em uso por aqueles que habitam nesses espaços, assim como de suas atividades socioculturais. E, mais que isso, perde-se um contexto específico que favorece o estabelecimento de teorias sobre a formação de uma variedade linguística em tempo real.

Fundamentados por esse propósito, portanto, reuniu-se um corpus por meio de quarenta entrevistas, divididas equitativamente entre o grupo dos pioneiros, com mais de 50 anos, e os jovens, de 18 a 40 anos, filhos ou netos desses pioneiros, sendo vinte sujeitos masculinos e vinte femininos em cada uma dessas faixas etárias distintas. Dessas entrevistas, dezesseis foram feitas em Sinop, oito em Vera, oito em Santa Carmem e oito em Cláudia, nas quais se utilizou, como guia, a versão final do questionário linguístico do aspecto semântico-lexical (QSL) do Projeto ALiB.

No entanto, tendo em mãos transcrições de relatos de experiência pessoal de vinte migrantes dos pontos de inquérito pesquisados, e por compreendermos que o repertório verbal da comunidade linguística em que se realizou a pesquisa apresenta peculiaridades e particularidades de acordo com a realidade dos falantes, foi elaborado um questionário semântico-lexical específico, com 210 questões, mantendo-se, dentre elas, dezesseis questões originais do QSL do ALiB.

Dessa forma, para a perspectiva diatópica dos fatos considerados na pesquisa, fez-se uso dos pressupostos teórico-metodológicos delimitados pela dialetologia. Com a preocupação de construir situações de entrevista em que a fala casual ou espontânea encontre um lugar 
e possa emergir durante a coleta de dados, foram utilizados alguns procedimentos metodológicos da sociolinguística laboviana, tais como a observação do perfil dos sujeitos e sua organização sociocultural, a divisão genérica e níveis de instrução, assim como a postura a ser adotada pelo pesquisador e o método de entrevistas.

Compreendemos, desse modo, que toda a abundância de eventos e fatos disponibilizados pela história devem ser considerados quando se pensa no processo de "ramificação" que leva à formação do modo de falar local.

Nessa perspectiva, apresentam-se, neste texto, apenas as variantes lexicais do tema carne-seca dadas como resposta à seguinte questão: qual o nome ...para a tira larga de carne bovina salgada, seca ao sol, e depois empacotada para a venda em estabelecimentos comerciais?

\section{Alinhavos de análise}

No contexto de utilização responsiva, nos quatro pontos selecionados, é possível observar a confluência social, cultural, econômica e histórica que leva ao encontro da norma semântico-lexical do português falado na região ou, conforme Salomão (2011, p. 190), à "regularidade e sistematicidade por trás do aparente caos da comunicação no dia-a-dia".

Essa reflexão pauta-se, inicialmente, no molde estatístico idealizado por Muller (1968), que tem, como propósito, mensurar e analisar estruturas linguísticas. Destacamos, também, os conceitos fundamentais que abarcam esse fenômeno da linguagem, que são os relacionados à distinção tripartida apresentada por Coseriu (1979) entre sistema, norma e fala. É importante compreender, tal como exposto por esse autor, que, para os falantes de uma língua, a funcionalidade atual implica sempre em uma superação do "atual estado de língua" para o futuro. Dessa maneira, "a língua atual não é apenas conjunto de formas já realizadas, modelos atualizáveis, mas também é técnica para ultrapassar o realizado, 'sistema de possibilidades' (sistema)" (COSERIU, 1979, p. 231).

Para Coseriu, há, pois, um conjunto de normas sociais na fala coletiva de uma comunidade que deve ser considerado em um estudo geolinguístico, bem como é necessário observar que uma língua histórica apresenta sempre variedades internas, que se alinhavam, essencialmente, a partir das diferenças geográficas (aspectos diatópicos), entre os estratos socioculturais de uma comunidade linguística (aspectos diastráticos) ou ainda entre os distintos tipos de modalidade expressiva (aspectos diafásicos). 
Barbosa (1989, p. 573) ainda afirma que a norma tem também um aspecto quantitativo, além do qualitativo, pois "uma norma de grupos de indivíduos, por exemplo, se define, de um ponto de vista, como conjunto de modelos de realizações concretas, e de outro, como o conjunto dos fatos de alta freqüência e distribuição regular nos discursos dos sujeitos falantes".

Dessa forma, para a verificação da norma, assim como da distribuição (regularidade e sistematicidade) das variantes léxicas do tema carne-seca, apresentamos as subsequentes tabela e figura:

Tabela 1 - Distribuição das variantes léxicas do tema carne-seca

\begin{tabular}{|c|c|c|c|c|c|c|c|c|c|c|c|c|c|c|c|c|c|c|}
\hline \multirow{2}{*}{\multicolumn{2}{|c|}{$\begin{array}{l}\text { Ponto } \\
\text { Faixa etária }\end{array}$}} & \multicolumn{4}{|c|}{ Sinop } & \multicolumn{4}{|c|}{ Vera } & \multicolumn{4}{|c|}{ Cláudia } & \multicolumn{4}{|c|}{ Santa Carmem } & \multirow[t]{2}{*}{ Total } \\
\hline & & \multicolumn{2}{|c|}{$\begin{array}{l}\text { Ma is } \\
\text { de } 50 \\
\text { anos }\end{array}$} & \multicolumn{2}{|c|}{$\begin{array}{l}18 / 40 \\
\text { anos }\end{array}$} & \multicolumn{2}{|c|}{$\begin{array}{l}\mathrm{Ma} \text { is } \\
\text { de } 50 \\
\text { anos }\end{array}$} & \multicolumn{2}{|c|}{$\begin{array}{l}18 / 40 \\
\text { anos }\end{array}$} & \multicolumn{2}{|c|}{$\begin{array}{l}\mathrm{Ma} \text { is } \\
\text { de } 50 \\
\text { anos }\end{array}$} & \multicolumn{2}{|c|}{$\begin{array}{l}18 / 40 \\
\text { anos }\end{array}$} & \multicolumn{2}{|c|}{$\begin{array}{l}\mathrm{M} \text { a is } \\
\text { de } 50 \\
\text { anos }\end{array}$} & \multicolumn{2}{|c|}{$\begin{array}{l}18 / 40 \\
\text { anos }\end{array}$} & \\
\hline Sexo & & M & $\mathrm{F}$ & M & F & M & $\mathrm{F}$ & M & $\mathrm{F}$ & M & $\mathrm{F}$ & M & F & M & $\mathrm{F}$ & M & $\mathrm{F}$ & \\
\hline \multirow{10}{*}{ Lexia } & $\begin{array}{l}\text { c a } r n e \\
\text { defumada }\end{array}$ & & & & & & & & & & & 1 & & & & & & 01 \\
\hline & $\begin{array}{l}\text { carne-de- } \\
\text { sal }\end{array}$ & & & & & & & & 1 & & & & & & & & 1 & 02 \\
\hline & $\begin{array}{l}\text { carne-de- } \\
\text { sol }\end{array}$ & 4 & 2 & 4 & 3 & & & 2 & 1 & 1 & 2 & & 2 & 1 & 1 & 1 & 2 & 26 \\
\hline & $\begin{array}{l}\text { c a r n e } \\
\text { muqueada }\end{array}$ & 1 & & & & & & & & & & & & & & & & 01 \\
\hline & $\begin{array}{l}\text { c a r n e } \\
\text { salgada }\end{array}$ & & & & & & & & & & & & & & & 1 & & 01 \\
\hline & $\begin{array}{l}\text { c a rne - } \\
\text { seca }\end{array}$ & 4 & 3 & & 3 & 1 & 2 & 1 & 2 & 1 & 2 & 2 & 2 & 2 & 2 & 1 & 2 & 30 \\
\hline & charque & 4 & 1 & 4 & 3 & 1 & 1 & 2 & 1 & 2 & 2 & 1 & 1 & 2 & 1 & 1 & 2 & 29 \\
\hline & jabá & 2 & 1 & 2 & 1 & 1 & 1 & 2 & & 2 & & 1 & & 2 & 2 & 1 & & 18 \\
\hline & manta & & & & & & 1 & & & & & & & & & & & 01 \\
\hline & Total & 15 & 7 & 10 & 10 & 3 & 5 & 7 & 5 & 6 & 6 & 5 & 5 & 7 & 6 & 5 & 7 & 109 \\
\hline
\end{tabular}




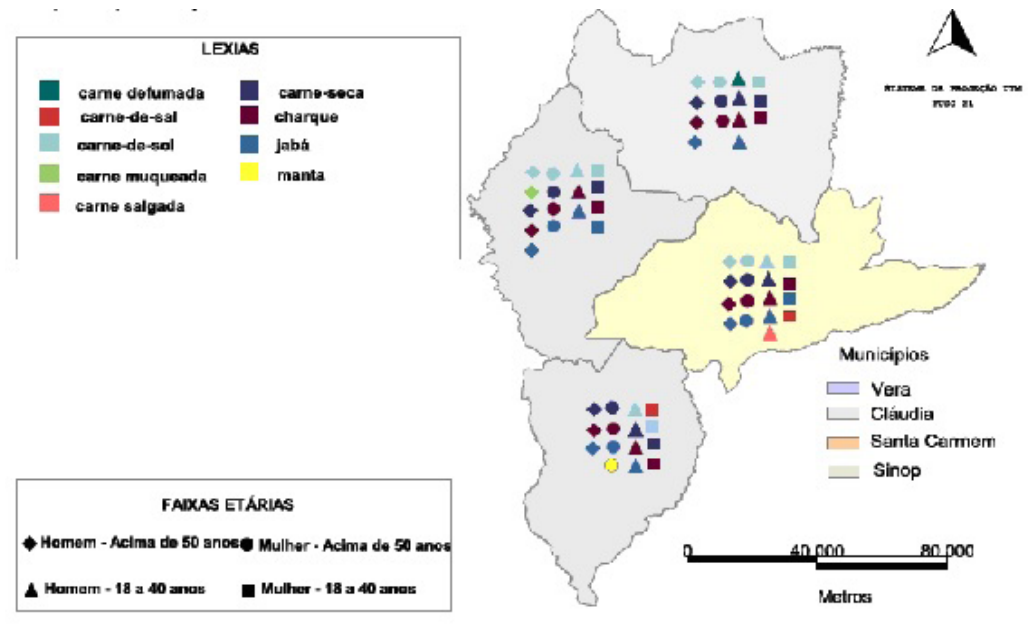

Figura 3 - Cartogramas: carne-seca

Na tabela, como também se verifica na figura 3, o item lexical com maior ocorrência é carne-seca, com trinta respostas distribuídas em todos os quatro pontos. Esse item traz, como frequência, um número maior de respostas femininas, dezoito, versus doze masculinas, assim como uma maior quantificação de respostas dadas por sujeitos com mais de 50 anos, dezessete, contra treze menções entre jovens de 18 a 40 anos.

Quanto ao item lexical charque, ele aparece como segunda maior ocorrência, com vinte e nove registros localizados em todos os pontos de inquérito. Destas ocorrências, dezessete foram manifestadas por homens e doze por mulheres, das quais quatorze foram expressas pelo grupo com mais de 50 anos e quinze pelo grupo com idade de 18 a 40 anos.

$\mathrm{O}$ item carne-de-sol evidencia-se como terceira maior ocorrência, com vinte e seis respostas apreendidas em todas as quatro cidades, tendo sido realizadas pelo mesmo número de sujeitos masculinos e femininos, treze citações de ambos. Ressalta-se que há maior preferência de uso desta lexia entre os jovens, que a disseram quinze vezes, contra as onze realizações entre os entrevistados acima de 50 anos.

${ }^{5}$ Este termo, cunhado por Cristianini (2007), é utilizado para retratar os fenômenos linguísticos de uma área específica a ser explorada, no caso deste estudo para mostrar as variantes léxicas do tema carne-seca distribuídas nos pontos de inquérito. 
O item lexical jabá é a quarta maior ocorrência, com dezoito respostas que se encontram, também, em todos os pontos de estudo, divididas entre um número bem maior de realizações feitas por informantes masculinos, treze, versus apenas cinco entre as mulheres, bem como por uma maior quantidade de respostas dadas pelos sujeitos com mais de 50 anos, onze, contra sete feitas pelos jovens.

Carne salgada foi dita unicamente por um rapaz, da faixa de 18 a 40 anos, em Santa Carmem, assim como carne defumada, em Cláudia, enquanto carne-de-sal foi dada como resposta apenas por duas moças, de 18 a 40 anos, uma de Vera e uma de Santa Carmem.

$\mathrm{E}$, finalmente, os itens lexicais com ocorrência apenas entre os pioneiros, com mais de 50 anos, carne muqueada, dita por um homem de Sinop, e manta, por uma mulher de Vera.

\subsection{Carne-seca: apontamentos sócio-semântico-lexicais}

A lexia composta carne-seca teria se originado a partir das técnicas para a secagem de carnes utilizadas por um português residente no nordeste, chamado José Pinto Martins, por volta de 1790. Nesse período:

Os moradores desta região aproveitavam o clima seco para secar a carne e também propiciava durabilidade, já que não havia aparelhos de refrigeração. Logo depois, houve uma migração desses produtores para o Rio Grande do Sul, onde a prefeitura da cidade de Pelotas financiou a estrutura para o processo de fabricação do charque. [...] (nome que vem do dialeto quíchua xarqui, língua dos índios que habitavam a região dos Andes), que é preparado de modo similar ao da carne-seca. O diferencial está na maior quantidade de sal e de exposição ao sol ao qual o charque é submetido, o que lhe garante uma maior durabilidade. (PAINEIRA, 2014)

Nesse mesmo período (séc. XVIII), agora segundo o relato diacrônico de Schreiner (2012, p. 21-22), uma grande seca castigou o Nordeste do Brasil, especialmente o Estado do Ceará, que produzia um tipo de carne salgada e seca ao sol, chamada de carne-do-ceará. A grande seca, conhecida pelo nome de "seca dos três setes" (1777), praticamente extingue a produção de carne-seca nordestina. Mediante esse cenário, um fabricante de carne-do-ceará, de espírito empreendedor, desgostoso 
com a forte estiagem, decidiu atravessar o país mudando a história rio-grandense ao instalar a primeira charqueada às margens do Arroio Pelotas. Mas o debate sobre a veracidade histórica parece aproximarse ao debate etimológico, incitando dúvidas sobre a consideração de José Pinto Martins como o primeiro charqueador. O que não levanta nenhum questionamento, porém, é que José Pinto Martins introduziu, nas instalações às margens dos arroios, as técnicas usadas no Ceará, transformando-as em indústrias.

De acordo com Mennucci (2009, p. 26-28), historicamente a produção de carnes salgadas típicas brasileiras compreende a elaboração de produtos industrializados e, também, artesanais, podendo ser resumidas, conforme as técnicas empregadas, em carne-de-sol, carne-seca e charque. A diferença entre elas residiria, basicamente, na maneira de preparo, o que lhes conferiria características variadas. Contudo, todas têm em comum o fato de serem elaboradas, preferencialmente, de carne bovina:

Charque: É um produto industrializado. Para sua obtenção utilizase carne fresca bovina desossada, cortada em tiras ou mantas de 3 a $5 \mathrm{~cm}$ de espessura, dispostas em camadas. Aplica-se, sobre as mantas, uma injeção de salmoura (salga úmida), com cerca de $25,0 \%$ de cloreto de sódio. As mantas são lavadas e expostas ao sol para secagem por 40 a 42 horas, sendo cobertas por lonas impermeáveis para abafamento. Podem ser embaladas a vácuo ou não, estando prontas para comercialização.

Carne-seca: Obedece ao mesmo processo de elaboração do charque, porém recebe sal em menor quantidade. A secagem é feita com as carnes estendidas em varais expostos ao sol. O produto pode ser comercializado embalado ou a granel.

Carne-de-sol: É aquela preparada conforme o sistema nordestino, aplicando salga rápida, com imediata exposição ao sol após o abate. Deste modo, diferentemente das carnes salgadas citadas, a fabricação da carne-de-sol é artesanal, ausente de padronização e de tecnologia sofisticada, propiciando elaboração quase que doméstica. Submete-se a carne bovina e, eventualmente, a caprina, apenas a um leve processo de salga seca e secagem. É utilizada para acompanhar pratos regionais como o baião-de-dois, ou pode ser servida isoladamente, sob a forma de filé.

$\mathrm{O}$ verbete carne-seca aparece em dois dos quatro dicionários gerais selecionados para a averiguação semântico-lexical dos registros dos itens lexicais registrados nas entrevistas, no Novo dicionário da língua portuguesa (FERREIRA, 1986) e no Dicionário contemporâneo 
da língua portuguesa (AULETE DIGITAL, 2014). Eis os conceitos disponibilizados para este verbete, bem como para outros itens que são apontados pelos dicionaristas como sinônimos de carne-seca:

Quadro 1 - Tema carne-seca em dicionários

\begin{tabular}{|c|c|}
\hline Dicionário & Entrada \\
\hline $\begin{array}{l}\text { Vocabulario portuguez \& latino (BLUTEAU, } \\
1712 \text { ) }\end{array}$ & $\begin{array}{l}\text { CARNE SALGADA. Carne, que se póde } \\
\text { guardar muito tempo sem se corromper. (p. } 153 \text { ) }\end{array}$ \\
\hline $\begin{array}{l}\text { Novo dicionário aurélio da língua portuguesa } \\
\text { (FERREIRA, 1986) }\end{array}$ & $\begin{array}{l}\text { CARNE-SECA. Bras. V. charque. (p. 355) } \\
\text { CARNE-DE-SOL. Bras., N. e NE. Carne } \\
\text { levemente salgada e seca ao sol. (p. 355) } \\
\text { CARNE-DE-VENTO. Bras., S. e C. V. Carne- } \\
\text { de-sol. (p. 355) } \\
\text { CARNE-DO-CEARÁ. Bras., NE. V. charque. } \\
\text { (p. 355) } \\
\text { CARNE-DO-SERTÃO. Bras., V. carne-de-sol. } \\
\text { (p. 355) } \\
\text { CARNE-DO-SUL. Bras., CE. V. charque. (p. } \\
\text { 355) } \\
\text { JABÁ. (De provável origem tupi) Bras. V. } \\
\text { charque. (p. 977) } \\
\text { CHARQUE. (Do quíchua ch 'arqui, através do } \\
\text { espanhol platino charque) Bras. Carne de vaca, } \\
\text { salgada e em mantas; carne-do-ceará, carne-de- } \\
\text { ceará, ceará, carne-do-sul, carne-seca, carne- } \\
\text { velha, jabá, iabá, sambamba, sumaca. (p. 392) }\end{array}$ \\
\hline $\begin{array}{l}\text { Dicionário contemporâneo da língua } \\
\text { portuguesa (AULETE DIGITAL, 2014) }\end{array}$ & $\begin{array}{l}\text { CARNE-SECA. 1- Bras. O mesmo que charque. } \\
\text { CARNE-DE-SOL. 1 - Bras. N N.E. Carne } \\
\text { bovina fresca que se conserva em sal. CARNE- } \\
\text { DE-VENTO. Bras. V. carne de sol. } \\
\text { CARNE-DO-CEARÁ. Bras. V. charque. } \\
\text { CARNE-DO-SERTÃO. Bras. V. carne-de-sol. } \\
\text { CARNE-DO-SUL. Bras., Ceará. V. charque. } \\
\text { JABÁ. 1- Carne bovina salgada e prensada } \\
\text { em manta; carne-seca; charque. CHARQUE. } \\
\text { 1- Carne de gado bovino salgada e aberta em } \\
\text { mantas; carne-seca; jabá; carne-do-ceará. }\end{array}$ \\
\hline $\begin{array}{l}\text { Dicionário gaúcho brasileiro (BOSSLE, } \\
\text { 2003) }\end{array}$ & $\begin{array}{l}\text { CHARQUE. Carne de gado bovino, aberta em } \\
\text { mantas, salgada e seca. O mesmo que carne- } \\
\text { de-sol, carne-do-ceará, carne-do-sertão, carne-- } \\
\text { velha, jabá, sambamba, sumaca, carne-seca, } \\
\text { carne-do-sul, etc. (Do cast. Plat. charque.) (p. } \\
\text { 143, itálico nosso). }\end{array}$ \\
\hline
\end{tabular}




\begin{tabular}{|c|c|}
\hline Dicionário do Nordeste (NAVARRO, 2004) & $\begin{array}{l}\text { CARNE-DE-CEARÁ/CARNE-DE-JABÁ/ } \\
\text { CARNE-DO-CEARÁ/CARNE-DO-SUL/ } \\
\text { CARNE-VELHA. Carne de charque, ceará, } \\
\text { carne-seca. (p. 98, itálico nosso). CARNE-DE- } \\
\text { SOL. Carne salgada, cortada em tiras ou mantas, } \\
\text { e posta para secar em varais, ao sol; o mesmo } \\
\text { que carne-do-sertão e carne-de-vento. (p. 98) }\end{array}$ \\
\hline
\end{tabular}

De acordo com os dois dicionários que trazem a entrada carneseca, este item lexical seria sinônimo de outro, o item lexical charque. Dessa forma, consultou-se também, nestes mesmos dicionários, a conceituação trazida a este item lexical/sinônimo e verificamos ainda outros itens lexicais relacionados como idênticos ao sentido de charque. Assim, conforme estas inscrições e suas respectivas atribuições sinonímicas, é possível constatar que tanto em Ferreira (1986) quanto no Aulete não é apresentada a distinção proposta por Mennucci (2009), exposta acima, com características diferenciadas para charque, carneseca e carne-de-sol, visto que exibem o item lexical composto carne-seca com o mesmo significado de charque.

Há, portanto, nestes dicionários, apenas duas classificações, para as quais convergem outras possibilidades de emprego dos seguintes itens: carne-de-sol (carne-de-vento e carne-do-sertão) e charque (carne-doceará, carne-de-ceará, ceará, carne-do-sul, carne-seca, carne-velha, jabá, iabá, sambamba e sumaca). Salienta-se que semelhante divisão é feita no Dicionário do Nordeste (2004), reduzindo-se somente a quantidade de itens lexicais sinônimos. Já o Dicionário Gaúcho Brasileiro (2003) apresenta o verbete charque e não expõe nenhuma diferença conceitual no rol de itens registrados como sinônimos.

Por conseguinte, os significados que afluem de carne-seca e de seus sinônimos nesses dicionários manifestam semelhança ao sentido expresso na questão ...para a tira larga de carne bovina salgada, seca ao sol, e depois empacotada para a venda em estabelecimentos comerciais?.

Desta maneira, ainda que se tenha em Bluteau (1712) menção à carne salgada, cujo conceito revela afinidade à técnica de preparo da carne-seca, é somente a partir do século XX que se fixa e se dissemina em maior proporção esta lexia, bem como os itens que se mostram como sinônimos. Assim sendo, trazido ao norte mato-grossense desde o início de sua colonização, carne-seca evidencia, desde então, continuísmo semântico, que se expressa pelo uso normativo na região pesquisada. 


\subsection{A distribuição da lexia carne-seca pelos pontos de inquérito} carne-seca:

Apresentamos abaixo um histograma com a distribuição da lexia

Gráfico 1 - Histograma de carne-seca

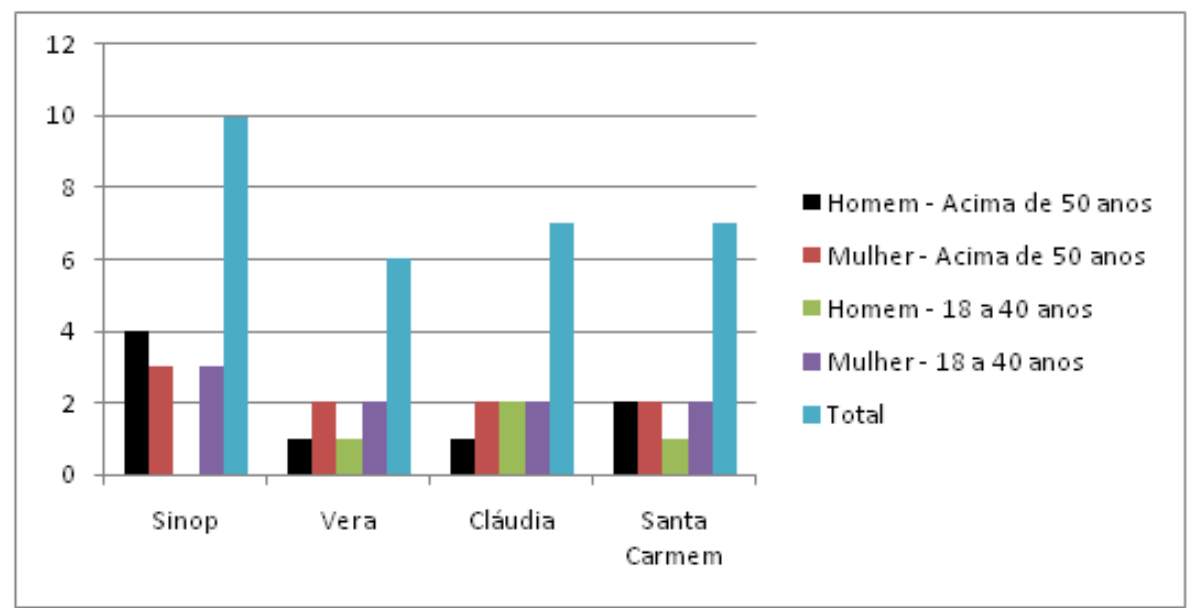

Segundo esse histograma, a lexia carne-seca localiza-se em todos os quatro municípios pesquisados, com trinta ocorrência ao todo. A sua distribuição ocorre da seguinte forma: na cidade de Sinop, sete sujeitos acima de 50 anos a utilizaram, quatro homens e três mulheres, bem como três mulheres, de 18 a 40 anos; nos pontos de Cláudia e de Santa Carmem, apenas dois dos dezesseis respondentes não mencionaram esse item lexical, mais especificamente um homem com mais de 50 anos de Cláudia e um rapaz, de 18 a 40 anos, de Santa Carmem; e, em Vera, um homem e duas mulheres acima de 50 anos, assim como um rapaz e duas moças, de 18 a 40 anos, fizeram referência à carne-seca.

Desse modo, como se pode perceber, há um número maior de respostas dadas pelos sujeitos femininos, dezoito, versus doze dos sujeitos masculinos. Assim como há maior ocorrência nas respostas de sujeitos com mais de 50 anos, dezessete, contra treze menções de entrevistados jovens, de 18 a 40 anos.

Além do item lexical carne-seca, manifestaram-se, ainda, nos dados coletados e transcritos, outros itens sinonímicos, assim distribuídos: carne-de-sol, carne muqueada, charque e jabá, em Sinop. 
No município de Vera há carne-de-sal, carne-de-sol, charque, jabá e manta. Em Cláudia, carne defumada, carne-de-sol, charque e jabá. E em Santa Carmem há, como concorrentes, carne-de-sal, carne-de-sol, carne salgada, charque e jabá. Dessa forma, afora carne-seca, há ainda os itens lexicais carne-de-sol, charque e jabá, com vinte e seis, vinte e nove e dezoito ocorrências, respectivamente, encontradas, também, em todos os pontos de inquérito. Fato este que exprime a concomitância de uso destes quatro itens na comunidade linguística pesquisada.

Destaca-se, contudo, que, distintamente da constatação de maior utilização do item lexical carne-seca por sujeitos acima de 50 anos, os itens carne-de-sol e charque são expressos por um número maior de sujeitos jovens, de 18 a 40 anos, quinze vezes para estes versus onze daqueles para carne-de-sol, enquanto charque foi proferido quinze vezes por jovens, de 18 a 40 anos, contra quatorze vezes por sujeitos com mais de 50 anos.

Este indicador serve como parâmetro para se testificar que esses dois itens lexicais concorrentes de carne-seca e jabá, têm sido a maior opção entre os jovens, fato que pode ser indício de maior continuidade de uso dos itens lexicais carne-de-sol e charque na comunidade linguística em análise.

É interessante verificar, contudo, que, em muitos casos, como o de um dos pioneiros de Sinop, natural de Santa Catarina, há realização de todos esses itens lexicais concomitantemente. Esse amálgama linguístico, que se constituiu desde o início da colonização desse espaço geográfico, é apenas um prolongamento da cultura de conservação de alimentos adotada já no Brasil Colônia devido às necessidades de subsistência e de sobrevivência dos exploradores das matas e sertões, apresadores de índios, bandeirantes, mineradores, tropeiros e, finalmente, dos colonos que se deslocaram e ainda se deslocam em busca de 'progresso' em novas terras com o intuito de desenvolvimento da agricultura, da pecuária ou do comércio. Foi nesse contexto, portanto, de acordo com Pinto e Silva (2008, p. 19), que surgiu:

Uma comida sem requinte, nem cerimônia, nem ritual, feita para se comer sozinho ou em grupos formados ao acaso. Um cardápio ordinário e comum, composto por farinha de milho, de mandioca, de peixe, um pedaço de carneseca e a mistura toda molhada pelo caldo de feijão, das favas ou das verduras, constituindo um tripé culinário no Brasil colonial. Há, pois, por trás desse sistema um modo 
particular de se fazer comida e de se comer, que fala, mais do que do alimento em si, sobre as maneiras originais de conservação nos trópicos, sobre os ajustes à subsistência e à sobrevivência, sobre a negociação entre valores como hierarquia, desigualdade e fome.

A referência à expressão carne muqueada, feita por um dos migrantes de Sinop, remete, também, à cultura primitiva de conservação das carnes, visto que, segundo Damásio (2009), para se conservar as carnes provenientes das caçadas, os habitantes das terras brasileiras utilizavam o moquém, uma técnica que consistia em expor a carne por longo período ao fogo até que esta perdesse completamente seu suco, mas sem queimá-la. Esta autora relata, ainda, que os índios não conheciam o sal mineral e que para realçar o sabor das carnes empregavam o sal obtido das cinzas de determinadas plantas que eles tostavam.

\section{Temperos finais}

À semelhança dessa amálgama de falares, que mostra a constituição linguística do português usado no norte de Mato Grosso, encontra-se o rol de itens lexicais usados pelos sujeitos entrevistados, nas regiões sul e sudeste, na resposta à seguinte pergunta na pesquisa de Schreiner (2012): Que nome você dá para a carne bovina preparada com sal que serve para fazer arroz-carreteiro, escondidinho, feijoada etc. Esta carne geralmente é vendida embalada à vácuo e não precisa de refrigeração?.

Dentre as respostas obtidas, destacam-se exatamente os quatro itens mais utilizados na região norte mato-grossense _charque, carneseca, carne-de-sol e jabá, que foram assim disponibilizados nos Estados do Rio Grande do Sul, de Santa Catarina e de São Paulo:

Parte-se de Pelotas para início das análises, por ser considerada a cidade núcleo das charqueadas, onde foram tabulados os seguintes números: das 336 entrevistas, 87 foram realizadas nesse município, representando $26 \%$ do total. Destes 87 informantes, 82 responderam charque, o que representa um total de $94 \%$ das respostas. As respostas restantes dividem-se em carne-seca e churrasco. [...] Em Florianópolis, das 336 entrevistas, foram aplicados os questionários com 64 informantes, representando assim $19 \%$ do total. As respostas obtidas foram as seguintes: 
33 pessoas, que equivalem a $52 \%$ dos informantes, responderam charque para a pergunta feita, sendo carneseca a segunda lexia mencionada por 20 informantes, em um total de $31 \%$. Respostas como carne-de-sol, jabá, carne salgada e carne de feijão também foram mencionadas. [...] Na cidade de São Paulo, em um total de 154 entrevistas, que representaram $46 \%$ do total de questionários aplicados, apenas 12 (8\%) dos informantes responderam charque. Em contrapartida, a lexia carne-seca foi mencionada por 111 informantes, o que corresponde a $72 \%$ das entrevistas. Já carne-de-sol e jabá representaram $9 \%$ e 4\%, respectivamente. (SCHREINER, 2012, p.459).

De acordo com esta amostragem pontuada por Schreiner, pode-se concluir maior afinidade do falar nas cidades de Sinop, Vera, Cláudia e Santa Carmem, com o léxico disseminado no sudeste do Brasil. Sendo assim, o item lexical carne-seca, ao lado de carne-de-sol, charque e em menor proporção de jabá, reforça o âmbito de usos linguísticos existentes na tradição histórica e cultural da comunidade em foco, o que evidencia continuísmo destes sentidos ligados a estes itens, sem esquecer, conforme vimos, que há realizações entre os jovens dos itens lexicais carne-de-sol e charque.

O resultado dessa análise, então, sugere que as influências regionais que constituíram e ainda constituem o português falado no norte de Mato Grosso são oriundas do contato de todos os dialetos e idioletos trazidos pelos migrantes de suas regiões de origem. Trata-se, portanto, de um recorte da linguagem utilizada nessa comunidade para representar o mundo sociocultural que a cerca.

\section{Referências}

ALMEIDA, E. de. Língua da fronteira: uma cartografia discursiva. In: BARONAS, R. L. Estudos discursivos em Mato Grosso: limiares. São Carlos/Cuiabá: Pedro \& João Editores/Ed. UFMT, 2008.

AULETE DIGITAL. Dicionário contemporâneo da língua portuguesa. Disponível em: <http://www.auletedigital.com.br>. Acesso em: ago. a set. 2014.

BARBOSA, M. A. Da microestrutura dos vocabulários técnico-científicos In: Anais do IV encontro nacional da ANPOLL. Recife: ANPOLL, 1989. 
BLUTEAU, R. Vocabulario portuguez e latino. Coimbra: Collegio das Artes da Companhia de Jesus, 1712.

BOSSLE, J. B. A. Dicionário gaúcho brasileiro. Porto Alegre: Artes e Ofícios, 2003. [1947]

CARDOSO, S. A. M. A Dialectologia no Brasil: perspectivas. D.E.L.T.A, São Paulo, v. 15, n. esp., p. 233-255, 1999.

COMITÊ NACIONAL DO PROJETO ALiB. Atlas lingüístico do Brasil: questionário 2001. Londrina: Ed. UEL, 2001.

COSERIU, E. Sincronia, diacronia e história: o problema da mudança lingüística. Trad. Carlos Alberto da Fonseca e Mário Ferreira. São Paulo: Presença, 1979.

CRISTIANINI, A. C. Atlas semântico-lexical da Região do Grande ABC. Tese (Doutorado em Filologia e Língua Portuguesa). - Faculdade de Filosofia, Letras e Ciências Humanas, Universidade de São Paulo, São Paulo 2007.

DAMÁSIO, M. V. F. R. Desenvolvimento da civilização e colonização do Brasil: a importância antropológica e cultural da salga como método natural de desidratação da carne. Monografia (Especialização em Gastronomia e Segurança Alimentar). 2009. Universidade de Brasília, Brasília, 2009.

FERREIRA, A. B. Novo dicionário da língua portuguesa. 2. ed. rev. e ampl. 4. imp. Rio de Janeiro: Nova Fronteira, 1986.

IBGE (INSTITUTO BRASILEIRO DE GEOGRAFIA E ESTATÍSTICA). Resultados do Censo. Dados do censo 2010 publicados no Diário Oficial da União. Rio de Janeiro: nov. de 2010. Disponível em: <http://www. censo2010.ibge.gov.br/dados_divulgados/index.php?uf=51>. Acesso em: 20 set. 2014.

MENNUCCI, T. A. Avaliação das condições higiênico-sanitárias da carne-de-sol comercializada em "casas do norte" no município de Diadema - SP. 2009. Dissertação ( Mestrado). Faculdade de Saúde Pública, Universidade de São Paulo, São Paulo, 2009.

MIRANDA, L.; AMORIN, L. Mato Grosso: atlas geográfico. Cuiabá: Entrelinhas, 2001.

MULLER, C. Initiation à la statistique linguistique. Paris: Librarie Larousse, 1968. 
MÜLLER, G.; CARDOSO, F. H. Amazônia: expansão do capitalismo. São Paulo: Brasiliense/CEBRAP, 1977.

NAVARRO, F. Dicionário do Nordeste: 5000 palavras e expressões. São Paulo: Estação Liberdade, 2004. [1956].

NASCENTES, A. O linguajar carioca. Rio de Janeiro: Simões, 1953.

OLIVEIRA, J. M. de. A esperança vem na frente: contribuição ao estudo da pequena produção em Mato Grosso, o caso Sinop. Dissertação (Mestrado) ). - Faculdade de Filosofia, Letras e Ciências Humanas, Universidade de São Paulo, São Paulo, 1982.

PAINEIRA. Notícias. Paineira Alimentos é história da carne-seca no Brasil. Disponível em: $<$ http://www.paineira.net/mais_noticias. php?id=30\#>. Acesso em: 20 set. 2014.

PANOSSO NETTO, A. Vera: a princesinha do nortão: uma contribuição ao estudo da ocupação da Amazônia mato-grossense. Campo Grande: A. Panosso Netto, 2000.

PHILIPPSEN, N. I. A constituição do léxico norte mato-grossense na perspectiva geolinguística: abordagens sócio-semântico-lexicais. 2013. Tese (Doutorado em Filologia e Língua Portuguesa). - Faculdade de Filosofia, Letras e Ciências Humanas, Universidade de São Paulo, São Paulo 2013.

PINTO E SILVA, P. A cozinha da colônia. Revista Textos do Brasil, ed. $\mathrm{n}^{\circ} 13$ - Sabores do Brasil. Ministério das Relações Exteriores: Departamento Cultural, 2008. p. 14-19.

ROJETO ATLAS LINGUÍSTICO DO BRASIL. Critérios de seleção de localidades. Salvador, 2013a. Disponível em: $<$ http://twiki.ufba.br/twiki/ bin/view/Alib/RedePontos>. Acesso em 20 set. 2014.

PROJETO ATLAS LINGUÍSTICO DO BRASIL. Antenor Nascentes e a divisão dialetal do Brasil. Salvador, 2013b. Disponível em: $<$ http://twiki. ufba.br/twiki/bin/view/Alib/DivisaoDialetal>. Acesso em 20 set. 2014.

SALOMÃO, A. C. B. Variação e Mudança Linguística: panorama e perspectivas da sociolinguística variacionista no Brasil. Fórum Linguístico, Florianópolis, v. 8, n. 2, p. 187-207, 2011.

SCHREINER, C. Edição de documentos e estudo do vocabulário do charque na Região Sul do Brasil: contribuição à história do português 
brasileiro. 2012. Tese (Doutorado em Filologia e Língua Portuguesa). Faculdade de Filosofia, Letras e Ciências Humanas, Universidade de São Paulo, São Paulo 2012.

SOUZA, E. A. de. Sinop: história, imagens e relatos - um estudo sobre a sua colonização. Cuiabá: Instituto de Ciências Humanas e Sociais, 2004. 